\title{
A Systematic Review on the Synoptic Operative Report Versus the Narrative Operative Report in Surgery
}

\author{
Özgür Eryigit $^{1}$ (1) $\cdot$ Floyd W. van de Graaf ${ }^{1} \cdot$ Johan F. Lange $^{1}$
}

Published online: 2 May 2019

(C) The Author(s) 2019

\begin{abstract}
Background Proper documentation is an essential part of patient safety and quality of care in the surgical field. Surgical procedures are traditionally documented in narrative operative reports which are subjective by nature and often lack essential information. This systematic review will analyze the added value of the newly emerged synoptic reporting technique in the surgical setting.

Methods A systematic review was conducted to compare the completeness and the user-friendliness of the synoptic operative report to the narrative operative report. A literature search was performed in EMBASE, Ovid MEDLINE, Web of Science, Cochrane CENTRAL, and Google Scholar for studies published up to April 6, 2018. The Newcastle-Ottawa Scale was utilized for the risk of bias assessment of the included articles. PROSPERO registration number was: CRD42018093770.

Results Overall and subsection completion of the operative report was higher in the synoptic operative report. The time until completion of the operative report and the data extraction time were shorter in the synoptic report. One exception was the specific details section concerning the operative procedure, as this was generally reported more frequently in the narrative report. The use of mandatory fields in the synoptic report resulted in more completely reported operative outcomes with completion percentages close to $100 \%$.

Conclusions The synoptic operative report generally demonstrated a higher completion rate and a much lower time until completion compared to the traditional narrative operative report. A hybrid approach to the synoptic operative report will potentially yield better completion rates and higher physician satisfaction.
\end{abstract}

\section{Introduction}

In the current medicine, all healthcare providers are obliged to properly document the care services provided. Within this requirement lays the composition of the operative note, comprising the essence of a surgical intervention and an imperative part in the continuity of care [1]. For

Özgür Eryigit

o.eryigit@erasmusmc.nl

1 Department of Surgery, Erasmus MC - University Medical Center Rotterdam, H-173, P.O. Box 2040 3000 CA Rotterdam, The Netherlands decades, the narrative operative report (NR) has been used in this manner. This reporting method, however, is subjective by nature and often lacks essential information [2]. Given the fact that proper documentation is an essential part of patient safety and quality of care, many in the surgical field have experimented with or even have implemented synoptic reporting (SR) as a substitute. The word synopsis is derived from two ancient Greek words: бóv (sún, "with or whole") and öyıৎ (ópsis, "view") and can be interpreted as a concise description of-in this case -a surgical procedure. An SR provides summarized documentation containing predefined leading criteria of the surgical procedure, which can effortlessly be completed in 
computerized templates. This synoptic way of reporting can also be achieved by providing easily comprehensible aide-mémoires. By adding quality of care indicators to this documentation method, these factors can be monitored efficiently without the need for double entries in a separate report. A good example of an electronically stored SR can be found in a study by Vergis et al. [3] focusing on Rouxen-Y gastric bypass.

Worldwide, over seven million patients suffer major complications following surgery every year. One million of these patients will die during or immediately after surgery as a result. Around half of these adverse events are potentially preventable [4]. Checklist usage in surgery results in thousands of patients' lives being saved each year. One of the best-known examples is the 19-item WHO Surgical Safety Checklist which was developed to decrease errors and adverse events and increase teamwork and communication [5]. This checklist reduced morbidity and mortality rates by more than one-third across all participating hospitals.

Earlier publications determined the lack of available information in the traditional reports. Wauben et al. demonstrated that NRs in laparoscopic cholecystectomy contained fewer essential procedural steps compared to what could be seen on operative video recordings [2]. Another study on laparoscopic cholecystectomy concluded that cases with bile duct injury contained fewer key elements of the report than those without bile duct injury, a phenomenon likely caused by surgeons tending to focus more on reporting unusual events rather than reporting the essential steps of the operation [6]. Apart from this explanation, it is plausible that, due to medicolegal concerns and fear of litigation, surgeons may, consciously or not, omit some part of the operative report when intraoperative complications occur. Furthermore, several studies reported improved efficiency [7], higher patient acuity level [8], higher physician satisfaction [9], and reduced administrative costs [10] in SRs. However, the extent of the superiority of SR and the ideal construction of the operative report remain unknown.

This systematic review evaluates the completeness and user-friendliness of the SR and the NR in the surgical setting.

\section{Material and methods}

The study protocol was registered in the International Prospective Register of Systematic Reviews (PROSPERO, http://www.crd.york.ac.uk/prospero), prior to the start of the systematic review, with registration number CRD42018093770.

\section{Systematic literature search}

A systematic search was performed in EMBASE, Ovid MEDLINE, Web of Science, Cochrane CENTRAL, and Google Scholar for studies published up to April 6, 2018, comparing SRs to NRs. There was no limit in date of publication. The search was conducted in accordance with the Preferred Reporting Items for Systematic Reviews and Meta-Analyses (PRISMA) guidelines and limited to manuscripts written in English [11]. The complete search strategy is shown in "Appendix."

\section{Article selection and data extraction}

Two investigators (ÖE and FWvdG) independently reviewed articles using a standardized extraction form (Microsoft Excel-Microsoft Corp., Redmond, WA, USA). Disagreements were resolved through consensus or by consulting a third investigator (JFL). Studies were excluded if no comparison was made between SR and NR or when the intervention was used in a non-surgical setting. Specific types of articles were excluded: no available fulltext, non-original articles, surveys, case reports, animal or cadaveric studies, guidelines, protocols, conference abstracts, letters to the editor, replies, and editorials. Study parameters included: first author, publication year, study design, comparison method, surgery type, NR type, SR type, use of mandatory fields in the SR, number of cases, completeness of reporting, and time until completion and extraction of the report.

\section{Risk of bias assessment}

We utilized the Newcastle-Ottawa Scale (NOS) to grade the risk of bias of each included article [12]. The NOS comprises eight items, categorized into three groups: selection of study groups, comparability of groups, and ascertainment of the outcome of interest. A maximum of four points can be assigned to "Selection," two points to "Comparability," and three points to "Outcome." Stars were awarded for each item to depict the quality of each study. Studies of the highest quality can be awarded up to nine stars.

\section{Outcomes}

The primary outcome was reporting completeness with respect to the total number of reported variables in SRs and NRs. The secondary outcome was user-friendliness which was divided into time until completion and readability of the report. 


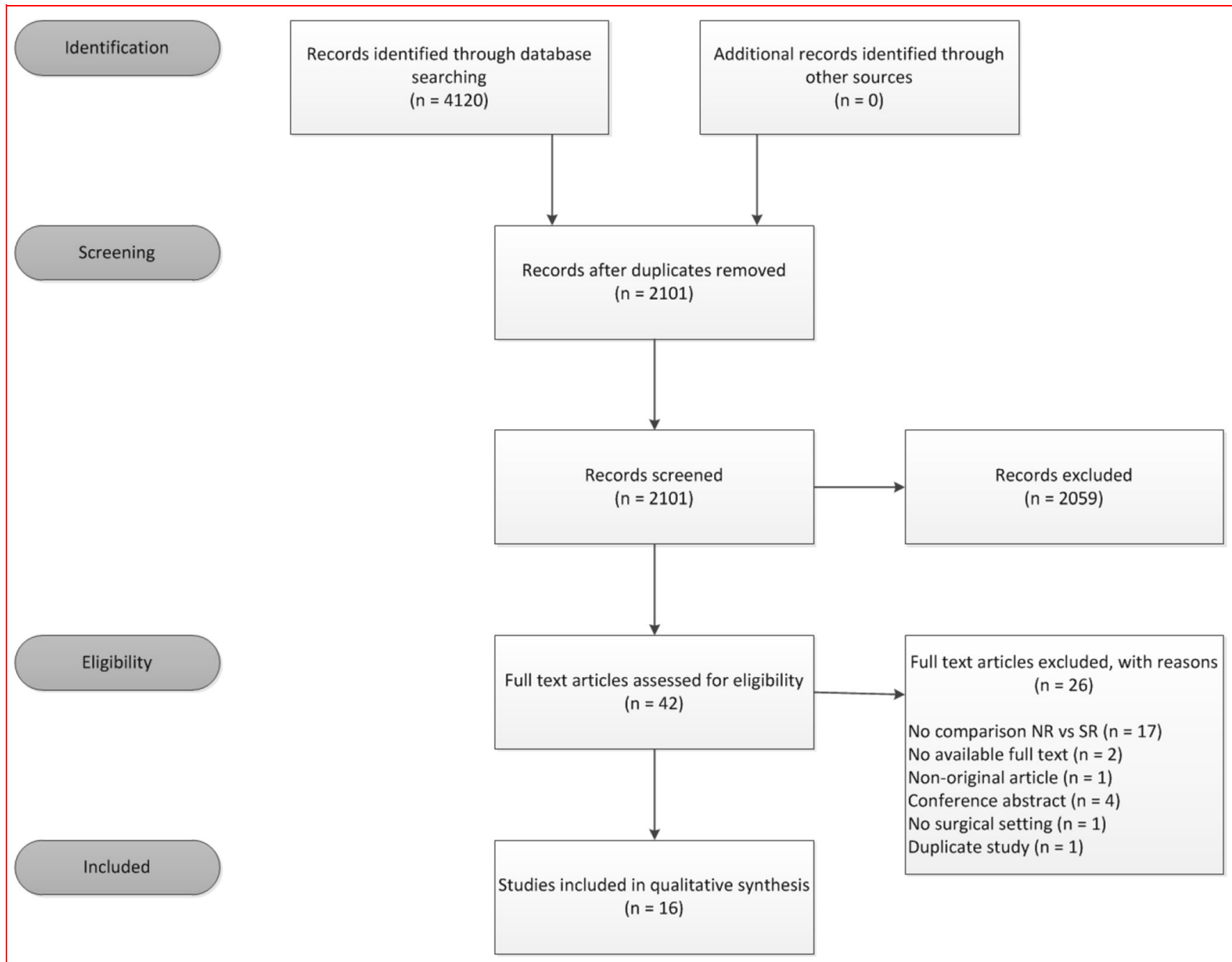

Fig. 1 PRISMA flow diagram of the study selection process

\section{Results}

\section{Literature search}

The initial search resulted in 4120 articles. After deduplication, 2101 studies were screened based on title and abstract. A total of 2059 articles were not relevant for the reviewed question. The eligibility of the remaining 42 articles was assessed based on full-text review, of which 16 met the inclusion criteria [13-28]. The study selection process is depicted in Fig. 1.

\section{Study characteristics}

Table 1 summarizes the study characteristics, and Table 2 reports the study results. In total, 2496 cases were present in the NR group and 1688 cases in the SR group. Eight studies compared retrospective cohorts to prospective cohorts, five studies compared prospective cohorts, and three studies compared retrospective cohorts. NRs were predominantly dictated $(56.3 \%)$, whereas SRs were primarily available as electronic template $(68.8 \%)$. Two studies utilized mandatory fields in their SRs.

\section{Quality of the included studies}

The NOS demonstrated that $93.8 \%$ of the studies earned above two stars for the Selection item, $18.8 \%$ of the studies earned above one star for the Comparability item, and $37.5 \%$ of the studies earned above two stars for the Outcome item (Table 3 ). These results suggest that nine studies $[16,17,19-24,28]$ could be considered of good quality and seven studies [13-15, 18, 25-27] of moderate quality. 


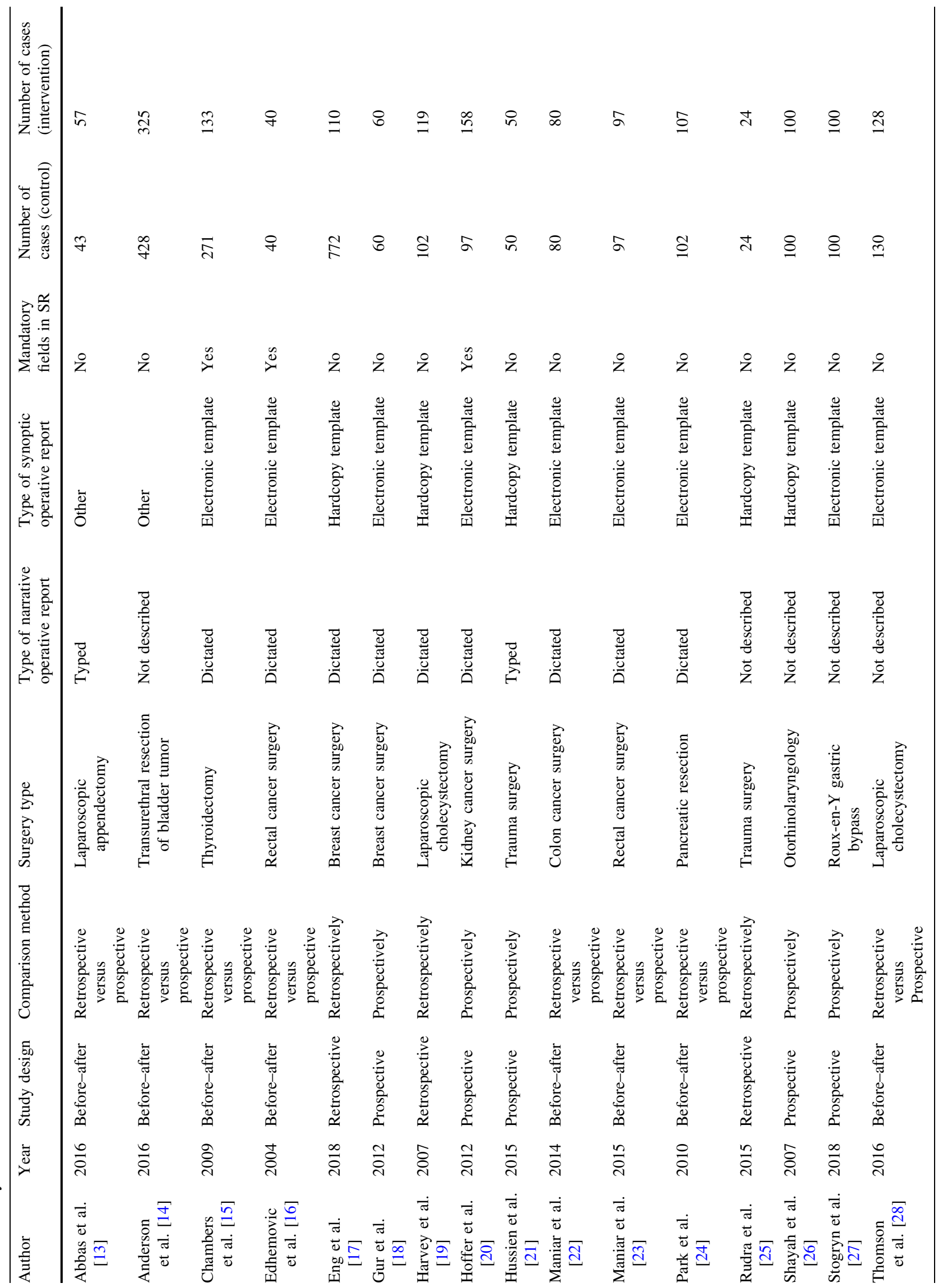


Table 2 Study results

\begin{tabular}{|c|c|c|c|c|}
\hline Study parameters ${ }^{\mathrm{a}}$ & Author & Year & Narrative report (mean \%) & Synoptic report (mean \%) \\
\hline \multirow[t]{10}{*}{$\begin{array}{l}\text { Overall } \\
\quad \text { completeness }\end{array}$} & $\begin{array}{l}\text { Abbas et al. } \\
\text { [13] }\end{array}$ & 2016 & $66 \%$ & $94 \%$ \\
\hline & $\begin{array}{l}\text { Edhemovic } \\
\text { et al. [16] }\end{array}$ & 2004 & $45.9 \%$ & $99 \%$ \\
\hline & $\begin{array}{l}\text { Eng et al. } \\
\quad[17]\end{array}$ & 2018 & $45 \%$ & $60 \%$ \\
\hline & $\begin{array}{l}\text { Gur et al. } \\
\text { [18] }\end{array}$ & 2012 & $66 \%$ & $94.7 \%$ \\
\hline & $\begin{array}{l}\text { Hoffer et al. } \\
\text { [20] }\end{array}$ & 2012 & $68 \%$ & $92 \%$ \\
\hline & $\begin{array}{l}\text { Hussien } \\
\quad \text { et al. [21] }\end{array}$ & 2015 & \multicolumn{2}{|c|}{$\begin{array}{l}\text { After introducing a standardized printed proforma, an overall significant improvement in the studiec } \\
\text { parameters was noticed }(p<.0134)\end{array}$} \\
\hline & $\begin{array}{l}\text { Maniar } \\
\text { et al. [22] }\end{array}$ & 2014 & $31.7 \%$ & $64.6 \%$ \\
\hline & $\begin{array}{l}\text { Maniar } \\
\text { et al. [23] }\end{array}$ & 2015 & $32.2 \%$ & $71.1 \%$ \\
\hline & $\begin{array}{l}\text { Park et al. } \\
\text { [24] }\end{array}$ & 2010 & $59.6 \%$ & $88.8 \%$ \\
\hline & $\begin{array}{l}\text { Stogryn } \\
\quad \text { et al. [27] }\end{array}$ & 2018 & $64.0 \%$ & $99.8 \%$ \\
\hline \multirow[t]{3}{*}{ Identifiers } & $\begin{array}{l}\text { Hussien } \\
\quad \text { et al. [21] }\end{array}$ & 2015 & Range $18-100 \%$ & Range $26-100 \%$ \\
\hline & $\begin{array}{l}\text { Rudra et al. } \\
\text { [25] }\end{array}$ & 2015 & Range $0-100 \%$ & Range $20.8-100 \%$ \\
\hline & $\begin{array}{l}\text { Shayah } \\
\text { et al. [26] }\end{array}$ & 2007 & Range $46-98 \%$ & $100 \%$ \\
\hline \multirow[t]{3}{*}{$\begin{array}{l}\text { Perioperative } \\
\text { information }\end{array}$} & $\begin{array}{l}\text { Gur et al. } \\
\quad[18]\end{array}$ & 2012 & $\begin{array}{l}\text { General and preoperative sections underreported in } \mathrm{I} \\
\text { intraoperative sections }(p=.001)\end{array}$ & NR compared to SR $(p=.004)$ also for \\
\hline & $\begin{array}{l}\text { Harvey } \\
\quad \text { et al. [19] }\end{array}$ & 2007 & Range $95-100 \%$ & Range $14-100 \%$ \\
\hline & $\begin{array}{l}\text { Maniar } \\
\quad \text { et al. [22] }\end{array}$ & 2014 & $\begin{array}{l}\text { Significantly higher scores on the patient-provider } \\
\text { discussion and laparoscopic cases sections }\end{array}$ & $\begin{array}{l}\text { Significantly higher scores on both } \\
\text { preoperative evaluation and operative care } \\
\text { data }\end{array}$ \\
\hline \multirow[t]{3}{*}{ Operative details } & $\begin{array}{l}\text { Eng et al. } \\
\text { [17] }\end{array}$ & 2018 & $57 \%$ & $59 \%$ \\
\hline & Harvey & 2007 & The use of a gallbladder retrieval bag $(63.0 \%)$ & The use of a gallbladder retrieval bag (57.8\%) \\
\hline & $\begin{array}{l}\text { et al. } \\
{[19]^{c}}\end{array}$ & & The size of the operative trocars $(58.0 \%)$ & The size of the operative trocars $(55.9 \%)$ \\
\hline \multirow[t]{5}{*}{$\begin{array}{l}\text { Postoperative } \\
\text { recommendations }\end{array}$} & $\begin{array}{l}\text { Abbas et al. } \\
\text { [13] }\end{array}$ & 2016 & $95 \%$ & $100 \%$ \\
\hline & $\begin{array}{l}\text { Hussien } \\
\quad \text { et al. [21] }\end{array}$ & 2015 & $100 \%$ & $100 \%$ \\
\hline & $\begin{array}{l}\text { Rudra et al. } \\
\text { [25] }\end{array}$ & 2015 & Range $25-100 \%$ & Range $83.3-100 \%$ \\
\hline & $\begin{array}{l}\text { Shayah } \\
\text { et al. [26] }\end{array}$ & 2007 & $94 \%$ & $100 \%$ \\
\hline & $\begin{array}{l}\text { Thomson } \\
\text { et al. [28] }\end{array}$ & 2016 & $95 \%$ & $100 \%$ \\
\hline
\end{tabular}


Table 2 continued

\begin{tabular}{|c|c|c|c|c|}
\hline Study parameters ${ }^{\mathrm{a}}$ & Author & Year & Narrative report (mean \%) & Synoptic report (mean \%) \\
\hline \multirow[t]{4}{*}{$\begin{array}{l}\text { Time until } \\
\text { completion }^{\mathrm{b}}\end{array}$} & $\begin{array}{l}\text { Edhemovic } \\
\text { et al. [16] }\end{array}$ & 2004 & - & $5: 59$ \\
\hline & $\begin{array}{l}\text { Hoffer et al. } \\
{[20]}\end{array}$ & 2012 & $2: 36$ & $2: 04$ \\
\hline & $\begin{array}{c}\text { Park et al. } \\
\text { [24] }\end{array}$ & 2010 & - & $4: 00 \pm 1: 36 \mathrm{SD}$ \\
\hline & $\begin{array}{l}\text { Stogryn } \\
\quad \text { et al. [27] }\end{array}$ & 2018 & $4: 50 \pm 0: 50 \mathrm{SD}$ & $3: 55 \pm 1: 26 \mathrm{SD}$ \\
\hline \multirow[t]{3}{*}{$\begin{array}{l}\text { Time until } \\
\text { extraction }^{\mathrm{b}}\end{array}$} & $\begin{array}{l}\text { Harvey } \\
\text { et al. [19] }\end{array}$ & 2007 & $2: 36$ & 2:04 \\
\hline & $\begin{array}{l}\text { Maniar } \\
\text { et al. [22] }\end{array}$ & 2014 & $4: 01 \pm 1: 14 \mathrm{SD}$ & $2: 32 \pm 0: 44 \mathrm{SD}$ \\
\hline & $\begin{array}{l}\text { Maniar } \\
\quad \text { et al. [23] }\end{array}$ & 2015 & $4: 48 \pm 1: 32 \mathrm{SD}$ & $2: 45 \pm 1: 36 \mathrm{SD}$ \\
\hline
\end{tabular}

${ }^{a}$ Mean percentages unless otherwise specified

b Time values are given in mean time (minutes:seconds)

c No statistically significant difference

\section{Completeness of reporting}

\section{Overall completeness}

Studies focusing on rectal and colon cancer surgery demonstrated that the range of retrieved information from SRs was 64.6-99.0\% compared to 31.7-45.9\% from NRs $[16,22,23]$. Breast cancer surgery showed similar results ranging from 60 to $94.7 \%$ for SRs and 45 to $66 \%$ for NRs $[17,18]$. Studies covering laparoscopic appendectomy, kidney cancer surgery, pancreatic resection, and Roux-en$\mathrm{Y}$ gastric bypass presented rates ranging from 88.8 to $99.8 \%$ for SRs and 59.6 to $68 \%$ for NRs [13, 20, 24, 27]. Necessary reporting items concerning transurethral bladder tumor resection significantly improved from .5 to $27 \%$ when surgeons were directed to consult a 10-item checklist before surgery and while entering the operative report $(p<.001)$ [14]. Reporting compliance in laparoscopic cholecystectomy showed an improvement from 53\% compliance in the first month of SR implementation to $67 \%$ compliance over the final 2 months of their study period [19]. Overall NRs in oncological thyroidectomies documented the presence/absence of tumor invasion in $27 \%$ of the cases, completeness of resection in $3 \%$, and tumor size in $29 \%$, whereas these were recorded in $100 \%$ of the cases in SRs $(p<.001)$ [15]. Other studies consistently showed higher overall completion rates in SRs [21, 25, 26, 28].

\section{Completeness of subsections}

Patient and surgeon identification, operation time and date, and operative diagnosis are examples of identifiers. One study demonstrated that prior to implementation of an operative note template, median completeness of identifiers was $81.65 \%$ (range $0-100 \%$ ) [25]. After implementation, a median completeness of $100 \%$ (range 20.8-100\%) was obtained. Surgeons performed suboptimally at recording the assistant's name (82\%), the operative diagnosis (46\%), the incision type $(87 \%)$, and the type of wound closure (83\%) [26]. $100 \%$ compliance in most identifiers was observed after provision of a printed aide-mémoire of a "Good Surgical Practice" guideline. An exception was that $18 \%$ of surgeons reported the surgery time and that surgeons were tended to report the surgery type in an emergency setting, but not when the procedure was performed electively.

The perioperative phase is the time period describing the duration of a patient's surgical procedure. In laparoscopic cholecystectomies, most perioperative and operative data were more completely reported in the SR (range 95-100\% in SR vs. range 14-100\% in NR) [19]. In colon cancer surgery, SRs were associated with significantly higher scores on both preoperative evaluation and operative care data [22]. NRs were also associated with significantly higher scores on the patient-provider discussion and laparoscopic cases sections. A prospective study to breast cancer operations concluded that surgeons underreported general and preoperative sections of the dictated report compared to the same items in the SR $(p=.004)$. This was also the case for intraoperative sections $(p=.001)$ [18].

In breast cancer surgery, technical operative details were completely reported in 59\% of SRs and in 57\% of NRs [17]. These technical details were divided into important and less important details. This division in subgroups 


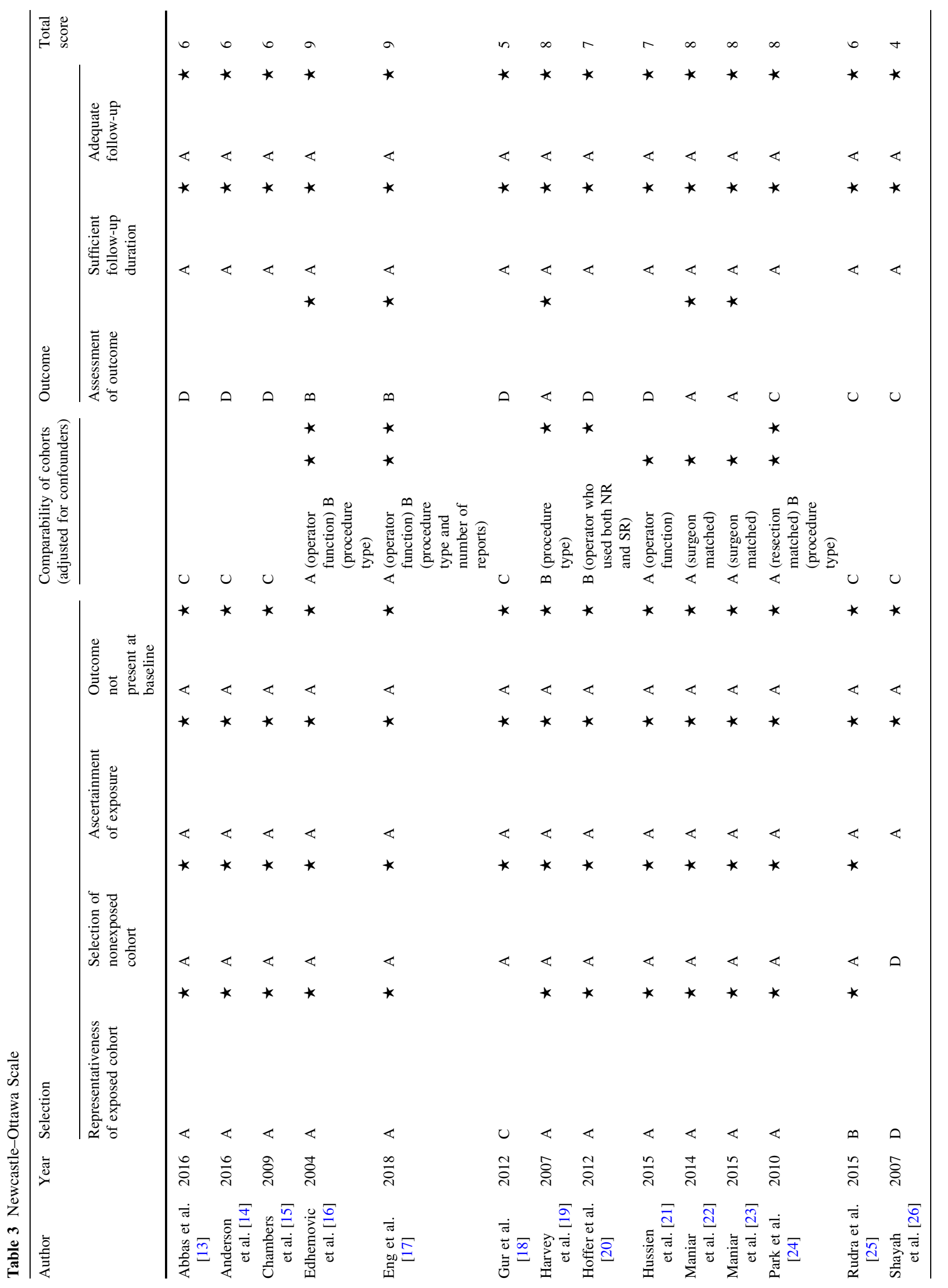




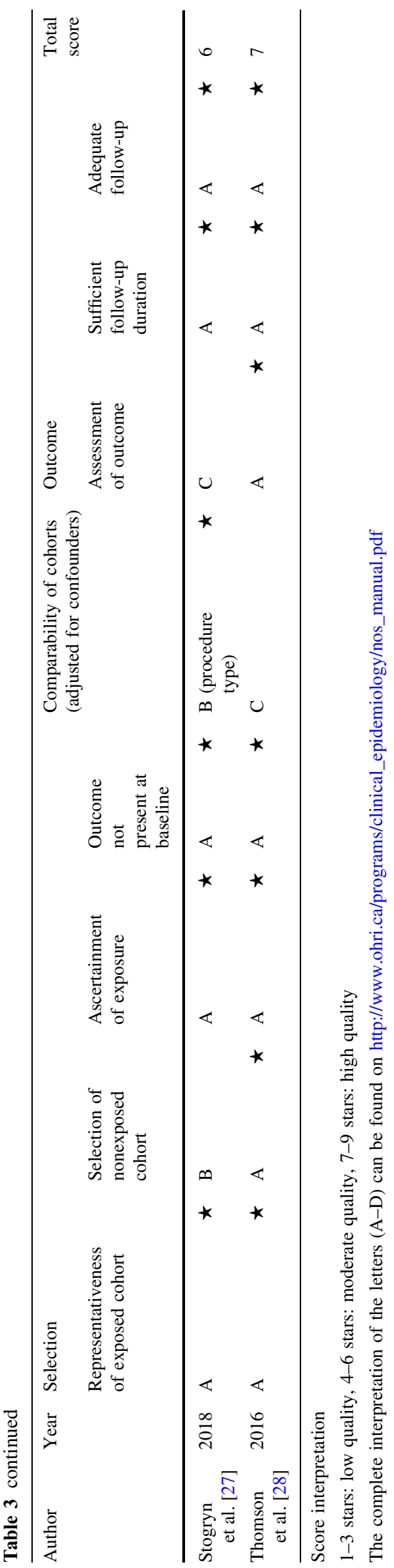

showed that important technical details were completely reported in $69 \%$ of SRs versus $58 \%$ of NRs. Contrarily, less important technical details were reported less frequently in SRs (44\% SR vs. 55\% NR). Furthermore, non-technical operative details showed a larger difference between both groups, favoring SR (61\% SR vs. $29 \%$ NR). Consistent to latter study, NRs of thyroidectomies routinely included nonessential information [15]. In laparoscopic cholecystectomy, operative details were more completely reported in the SR. Two exceptions were the use of a gallbladder retrieval bag ( $57.8 \%$ vs. $63.0 \%, p=.45)$ and the size of the operative trocars $(55.9 \%$ vs. $58.0 \%, p=.75)$ [19].

Improvements in the recording of postoperative instructions after laparoscopic appendectomy in the SR were not significant [13]. Prospectively reviewed trauma surgery reports also showed no completion rate differences in the postoperative plan sections for both SR (100\%) and NR (100\%) [21]. In a retrospective trauma surgery study, SRs yielded a median overall completion rate for postoperative instructions of $95.8 \%$ (range $83.3-100 \%$ ), whereas NRs had a median completion rate of $54.2 \%$ (range 25$100 \%$ ) [25]. In otorhinolaryngology, postoperative instructions were recorded in $94 \%$ of NRs. After the introduction of an aide-mémoire, $100 \%$ completion of this section was detected [26].

\section{User-friendliness}

The time until completion for SRs in rectal cancer surgery was approximately $6 \mathrm{~min}$ [16]. SRs for pancreatic resections took $4 \mathrm{~min} \pm 1.6 \mathrm{~min}$ SD to complete per case [24]. In an electronic SR used in kidney cancer surgery, a mean completion time (mean time (minutes:seconds)) of 2:04 was found in SRs and 2:36 in NRs [20]. SR completion times after Roux-en-Y gastric bypass were significantly shorter than NR completion times (mean time (minutes: seconds) \pm SD; SR 3:55 \pm 1:26 SD and NR 4:50 $\pm 0: 50$ SD, $p=.007)$ [27].

Three studies focusing on the readability of the operative report recorded shorter mean data extraction times in SRs compared to NRs in colon cancer surgery (mean time (minutes:seconds) SR 2:32 $\pm 0: 44$ SD and NR 4:01 $\pm 1: 14$ $\mathrm{SD}, p<.01$ ), rectal cancer surgery (mean time (minutes: seconds); SR 2:45 $\pm 1: 36 \mathrm{SD}$ and NR 4:48 $\pm 1: 32 \mathrm{SD}$, $p<.001$ ), and laparoscopic cholecystectomy (SR $124 \mathrm{~s}$ and NR 156 s) [19, 22, 23].

\section{Discussion}

In this review, we compared the completeness and userfriendliness of two surgical reporting techniques (SR and NR). All published studies comparing the two reporting 
designs have consistent conclusions. Overall completion and completion of subsections of the operative report were higher in SR. Subsequently, the time until completion and extraction of the operative report was shorter in SR. One exception to our findings was the specific details concerning the operative procedure, as this was reported generally higher in NRs. The main reason for this occurrence is most likely the lack of an extra comments section in most SR templates, in which the operator is able to report nonstandard, yet important events that have occurred during surgery.

Synoptic reporting methods were developed as a result of the lack of essential information in the NR. Despite the fact that new reporting techniques are being used more frequently, obtainment of scientific evidence regarding the extent of the added value and advantages of the SR was needed to promote further incorporation of synoptic reporting methods.

In 1994, a study was conducted on medical record keeping in which $70 \%$ of notes written by consultants were indecipherable in its present form by the nurse or junior doctor collecting the data [29]. To make usage of these poorly dictated or typed operative reports redundant, hospitals have implemented new reporting methods of which the Web-based reporting technique is the most commonly used computerized SR. It is designed to be user-friendly, and it can save data much faster and easier than the NR. Web-based reports, such as WebSMR (Surgical Medical Record), allow surgeons to securely access reports in the operating room or any other place connected to the Internet. It contains questions with drop-down menus and other functionalities, such as risk factor calculators and mandatory response fields for essential operative steps, to achieve a most comprehensive overview of the surgical procedure [30].

\section{Limitations}

The included articles focus on a diversity of surgical specialties, and just a few of these studies had similar surgical specialties [17-19, 21, 25, 28]. This could complicate the generalizability of the study outcomes. Seven articles were of moderate quality, which means that a proper understanding and comparability of these non-randomized studies are not fully ascertained. This could affect the interpretation and the quality of the data as presented [13-15, 18, 25-27]. Furthermore, we noticed that most articles compared a retrospective NR group to a prospective SR group. This way, it could be more difficult to accurately compare the two reporting methods, which might subsequently result in selection and information biases. Only a few articles were included with prospective comparisons of both reporting methods.

The analyzed data were not detailed enough to perform a pooled analysis. The previously mentioned differing surgical settings and comparison methods were also reasons not to pool the low number of studies. Each article utilized its own definitions for the different subsections in the operative reports, and these were not consistent between all studies.

Furthermore, it should be discussed that not all quality improvement projects on SR are published, which could result in higher risk of publication bias.

In general, all included studies favored SR. Nevertheless, advantages of NR and disadvantages of the current form of SR were also extensively reported. The use of mandatory fields in SRs resulted in more complete reporting with completion rates close to $100 \%$. The use of these fields is most likely the major contributor to the high disparity in completion rates between NRs and SRs. We noticed that SRs without mandatory fields showed a reduced yet still considerable difference between the two types of operative reports. Thus, the overall difference in completion rates favoring the SR can be detected in both SRs with and without mandatory fields.

Importantly, physicians could feel "forced" to use mandatory tools in this Web-based approach. This mindset might consequently result in less accurate reporting. However, feeling "forced" is not a physician's main mode of thought. New implementations are not easy to get accepted by physicians due to the idea that there could be an increased workload related to data entry and a big impact on current surgeon practices which could eventually affect timely patient care [31]. This impact is, in reality, minimal and, as this review demonstrates, the time until completion and extraction of the reports is shorter. It is thus important to inform physicians about the advantages of SR.

\section{Recommendations}

Our review demonstrates that the current form of the NR lacks much information and that there is still much room for improvement in the SR. The included studies contain a wealth of information on pitfalls of and tricks for the implementation method of a new operative report. Having evaluated all recommendations, we can strongly emphasize that for the purposes of education, for dealing with any unintended consequences of surgery, and for those faced 
with carrying out a subsequent operation, the description of exactly what was found, any unexpected findings such as anatomic variants, and any deviations from the planned procedure are all absolutely key to providing high-quality ongoing care to patients.

Taking into account the benefits and limitations of both reporting methods, a hybrid approach should be aimed for in which the SR and NR complement each other. In this approach, information can be stored without the use of mandatory fields for nonessential information with an additional narrative and/or video description of the procedure if possible. As mentioned before, it could be beneficial to implement an extra comments box for specific details and unusual observations as a standard section. By minimizing the variability of reporting across surgeons and by adding these important details to the current SR in a standardized way, abnormalities during surgery can be seen at a glance in this more extensive version of the SR.

\section{Conclusions}

Overall completeness of the SR is higher compared to the traditional NR. Likewise, subsections of the operative report show higher completion rates in the synoptic method. Furthermore, a much shorter time until completion and time until extraction was found in SRs, which could indicate higher user-friendliness. The narrative method generally demonstrated higher completion in specific details regarding the surgical procedure. A hybrid approach to the SR could give better completion rates and higher physician satisfaction.

Acknowledgements We want to thank biomedical information specialist Wichor Bramer of Erasmus MC Medical Library for conducting the search strategy. This review received no specific grant from any funding agency in the public, commercial, or not-for-profit sectors.

\section{Compliance with ethical standards}

Conflict of interest The authors declare that they have no conflict of interests.

Open Access This article is distributed under the terms of the Creative Commons Attribution 4.0 International License (http://crea tivecommons.org/licenses/by/4.0/), which permits unrestricted use, distribution, and reproduction in any medium, provided you give appropriate credit to the original author(s) and the source, provide a link to the Creative Commons license, and indicate if changes were made.

\section{Appendix}

See Table 4.

Table 4 Literature search strategy

\begin{tabular}{|c|c|}
\hline $\begin{array}{l}\text { Embase } \\
\text { 1950-April 6, } \\
\text { 2018) }\end{array}$ & $\begin{array}{l}\text { ((((synop* OR template* OR structured* OR structural* OR structuriz* OR structuris* OR standardi* OR checklist) } \\
\text { NEAR/3 (report* OR operati*-note* OR operati*-documentation* OR surg*-note* OR surg*-documentation*)) OR } \\
\text { (quality NEAR/3 (operati* OR surg*) NEAR/3 reporting)):ab,ti) AND ('surgery'/exp OR ‘surgeon'/exp OR 'operating } \\
\text { room'/de OR (surger* OR surgical* OR surgeon* OR ((operati*) NEAR/3 (room* OR theat* OR note* OR } \\
\text { documentation* OR report*))):ab,ti) NOT ([Conference Abstract]/lim OR [Letter]/lim OR [Note]/lim OR [Editorial]/lim) } \\
\text { AND [english]/lim }\end{array}$ \\
\hline $\begin{array}{l}\text { INE } \\
6,\end{array}$ & $\begin{array}{l}\text { (report* OR operati*-note* OR operati*-documentation* OR surg*-note* OR surg*-documentation*)) OR (quality ADJ3 } \\
\text { (operati* OR surg*) ADJ3 reporting)).ab, ti.) AND (exp Surgical Procedures, Operative/ OR exp surgeons/ OR exp } \\
\text { Operating Rooms/ OR (surger* OR surgical* OR surgeon* OR ((operati*) ADJ3 (room* OR theat* OR note* OR } \\
\text { documentation* OR report*))).ab, ti.) NOT (letter* OR news OR comment* OR editorial* OR congres* OR abstract* OR } \\
\text { book* OR chapter* OR dissertation abstract*).pt. AND english.la. }\end{array}$ \\
\hline $\begin{array}{l}\text { nce } \\
6 \text {, }\end{array}$ & $\begin{array}{l}\text { TS }=(((((\text { synop* OR template* OR structured* OR structural* OR structuriz* OR structuris* OR standardi* OR checklist) } \\
\text { NEAR/2 (report* OR operati*-note* OR operati*-documentation* OR surg*-note* OR surg*-documentation*)) OR } \\
\text { (quality NEAR/2 (operati* OR surg*) NEAR/2 reporting)) AND }((\text { surger* OR surgical* OR surgeon* OR }((\text { operati*) } \\
\text { NEAR/2 (room* OR theat* OR note* OR documentation* OR report*)))) AND DT }(\text { article) AND LA=(english) }\end{array}$ \\
\hline $\begin{array}{l}\text { 1998-April 6, } \\
\text { 2018) }\end{array}$ & $\begin{array}{l}\text { ((((synop* OR template* OR structured* OR structural* OR structuriz* OR structuris* OR standardi* OR checklist) } \\
\text { NEAR/3 (report* OR operati*-note* OR operati*-documentation* OR surg*-note* OR surg*-documentation*)) OR } \\
\text { (quality NEAR/3 (operati* OR surg*) NEAR/3 reporting)):ab,ti) AND ((surger* OR surgical* OR surgeon* OR } \\
\text { ((operati*) NEAR/3 (room* OR theat* OR note* OR documentation* OR report*))):ab,ti) }\end{array}$ \\
\hline $\begin{array}{l}\text { Google Scholar } \\
\text { (1991-April 6, }\end{array}$ & $\begin{array}{l}\text { "synopticlstructuredlstructural|structurized|structurised report|reporting"|"synopticlstructuredlstructurall } \\
\text { structurisedlstandardized operativeloperation|surgical noteldocumentation" surgerylsurgical|surgeon|"operativeloperating } \\
\text { roomltheater" }\end{array}$ \\
\hline
\end{tabular}




\section{References}

1. The Royal College of Surgeons of England Good Surgical Practice, London, England, 2014

2. Wauben LS, van Grevenstein WM, Goossens RH et al (2011) Operative notes do not reflect reality in laparoscopic cholecystectomy. Br J Surg 98:1431-1436

3. Vergis A, Stogryn SE, Mullan MJ et al (2017) Electronic synoptic reporting: assessing the completeness of synoptic and narrative reports for Roux-en-Y gastric bypass. Surg Obes Relat Dis 13:1863-1868

4. Weiser TG, Regenbogen SE, Thompson KD et al (2008) An estimation of the global volume of surgery: a modelling strategy based on available data. Lancet 372:139-144

5. Haynes AB, Weiser TG, Berry WR et al (2009) A surgical safety checklist to reduce morbidity and mortality in a global population. N Engl J Med 360:491-499

6. Stewart L, Hunter JG, Wetter A et al (2010) Operative reports: form and function. Arch Surg 145:865-871

7. van Walraven C, Laupacis A, Seth R et al (1999) Dictated versus database-generated discharge summaries: a randomized clinical trial. CMAJ 160:319-326

8. Grogan EL, Speroff T, Deppen SA et al (2004) Improving documentation of patient acuity level using a progress note template. J Am Coll Surg 199:468-475

9. Marill KA, Gauharou ES, Nelson BK et al (1999) Prospective, randomized trial of template-assisted versus undirected written recording of physician records in the emergency department. Ann Emerg Med 33:500-509

10. DeOrio JK (2002) Surgical templates for orthopedic operative reports. Orthopedics 25:639-642

11. Moher D, Liberati A, Tetzlaff J et al (2009) Preferred reporting items for systematic reviews and meta-analyses: the PRISMA statement. BMJ 339:b2535

12. Wells GA, Shea B, O'Connell D et al The Newcastle-Ottawa Scale (NOS) for assessing the quality of nonrandomised studies in meta-analyses. http://www.ohri.ca/programs/clinical_epide miology/oxford.asp. Accessed 30 Apr 2019

13. Abbas SH, Singh S, Sundran R et al (2016) A thorough note: does a procedure-specific operation note proforma for laparoscopic appendicectomy improve compliance with the Royal College of Surgeons of England Guidelines? Int J Surg 2:1-5

14. Anderson C, Weber R, Patel D et al (2016) A 10-Item checklist improves reporting of critical procedural elements during transurethral resection of bladder tumor. J Urol 196:1014-1020

15. Chambers AJ, Pasieka JL, Temple WJ (2009) Improvement in the accuracy of reporting key prognostic and anatomic findings during thyroidectomy by using a novel Web-based synoptic operative reporting system. Surgery (USA) 146:1090-1098

16. Edhemovic I, Temple WJ, de Gara CJ et al (2004) The computer synoptic operative report-a leap forward in the science of surgery. Ann Surg Oncol 11:941-947

17. Eng JL, Baliski CR, McGahan C et al (2018) Uptake and impact of synoptic reporting in a community care setting. Am J Surg 215 (5):857-861
18. Gur I, Gur D, Recabaren JA (2012) The computerized synoptic operative report: a novel tool in surgical residency education. Arch Surg 147:71-74

19. Harvey A, Zhang H, Nixon J et al (2007) Comparison of data extraction from standardized versus traditional narrative operative reports for database-related research and quality control. Surgery (USA) 141:708-714

20. Hoffer DN, Finelli A, Chow R et al (2012) Structured electronic operative reporting: comparison with dictation in kidney cancer surgery. Int J Med Inform 81:182-191

21. Hussien AS, Imam MA, Elsherbiny M et al (2015) Introducing a proforma to improve clinical care in trauma surgery. Br J Hosp Med (Lond) 76:472-474

22. Maniar RL, Hochman DJ, Wirtzfeld DA et al (2014) Documentation of quality of care data for colon cancer surgery: comparison of synoptic and dictated operative reports. Ann Surg Oncol 21:3592-3597

23. Maniar RL, Sytnik P, Wirtzfeld DA et al (2015) Synoptic operative reports enhance documentation of best practices for rectal cancer. J Surg Oncol 112:555-560

24. Park J, Pillarisetty VG, Brennan MF et al (2010) Electronic synoptic operative reporting: assessing the reliability and completeness of synoptic reports for pancreatic resection. J Am Coll Surg 211:308-315

25. Rudra S, Kieffer WK, Briffa N et al (2015) An opportunity in opnotes. J Perioper Pract 25:204-206

26. Shayah A, Agada FO, Gunasekaran S et al (2007) The quality of operative note taking: an audit using the Royal College of Surgeons Guidelines as the gold standard. Int J Clin Pract 61:677679

27. Stogryn SE, Hardy K, Mullan MJ et al (2018) Synoptic operative reporting: assessing the completeness, accuracy, reliability, and efficiency of synoptic reporting for Roux-en-Y gastric bypass. Surg Endosc Interv Tech 32:1729-1739

28. Thomson DR, Baldwin MJ, Bellini MI et al (2016) Improving the quality of operative notes for laparoscopic cholecystectomy: assessing the impact of a standardized operation note proforma. Int J Surg 27:17-20

29. Baigrie RJ, Dowling BL, Birch D et al (1994) An audit of the quality of operation notes in two district general hospitals. Are we following Royal College guidelines? Ann R Coll Surg Engl 76:810

30. Mack LA, Bathe OF, Hebert MA et al (2009) Opening the black box of cancer surgery quality: WebSMR and the Alberta experience. J Surg Oncol 99:525-530

31. Lapointe L, Rivard S (2006) Getting physicians to accept new information technology: insights from case studies. CMAJ 174:1573-1578

\section{Publisher's Note}

Springer Nature remains neutral with regard to jurisdictional claims in published maps and institutional affiliations. 